\title{
EXPERIENCE OF THE FINALITY OF LIFE: STRIVING TO LIVE MORE VALUABLY
}

\author{
Agnè Jurgaitytè-Avižinienè, Rimantas A. Kočiūnas \\ Vilnius University, Lithuania \\ E-mail: agne@pkc.It, rimask@parkas.It
}

\begin{abstract}
The aim of this study was to reveal the experience of finality of life of young adults and to develop a substantive theory, based on experience of young participants. In this research, the definition of death anxiety was operationalised and the term finality of life was used. Based on a distinctive philosophical background, this term enables to research the prevailing phenomenon in novel ways and to have a different look at its experience. The classical grounded theory (GT) method was chosen for the research as it empowers to study and explain the phenomenon in a variety of ways, to extract its key points and concepts, and to provide its theoretical construct. 18 healthy adults aged $22-45$ participated in the research. 2 in-depth interviews were conducted with each of the participants. They wrote a diary on the topic. The data was analysed using classical GT principles. Central theoretical component, core category, was named - striving to live more valuably. It discloses the extent to which participants deal with the main concern of this phenomenon - inevitability of death. Two subcategories emerge: finding a lively life and striving for subjective value of life. The latter is characterized as condition facilitation, satisfaction with life. The use of visual imagery for the explanation of the created theory help to reveal better the experiences, which are encountered by the young adults, while facing the finality of life or talking about this topic. It is expected that the present research will draw attention on the fact that in order to understand the human relationship with death and mortality, it is not sufficient to talk about avoidance and anxiety, it is necessary to speak about human desire to have a nice and valuable life.
\end{abstract}

Key words: finality of life, grounded theory, inevitability of death, striving to live more valuably.

\section{Introduction}

As a scientist starts taking an interest in the death psychology (thanatopsychology), he/she first encounters an abundance of literature, opinions of people, historical, religious, philosophical and other works and views. Thus, Neimeyer (2008), one of the most famous modern thanatologists, starts the introduction of the book about death by stating that "The field of death studies has a long history, but short memory" (p. 1). In a sense, human thinking about death is probably as old as the mankind itself. However, most of social sciences research the topic of death in a very simplistic, theoretically weak way, which prevents from seeing the deeper heritage of Western culture. As a consequence, there is a random, superficial distribution of correlations, which does not reach the human depths, linking us with mortality (Neimeyer, 2008). Moore and Williamson (2003), Tomer, Eliason and Wong (2008) also emphasize a multifactorial study of death phenomenon by highlighting the importance of culture, religions, philosophies and the position of public of that age, as well as its interdisciplinary aspect, and have shown the increased interest in this topic during the last decade (Hayes, Schimel, Arndt \& Fautcfer, 2010)

One of the difficulties, faced, while exploring the death phenomenon, is an abundant confusion of concepts. A lot of various terms and concepts for examining the death phenomenon are met both in 
literature and everyday life: the fear of death and dying, death anxiety, threat of dying, view towards death, concern about death, acceptance of death, finality of life, etc. The terms in this field are used in a quite free way without any accurate separation and definition (Jurgaitytė-Avižinienė \& Kočiūnas, 2004). They are used, while analyzing very different experience of people, often without going deep into the fact, what exact experience it is talked about, how comprehensively it describes the wellbeing and life of person, what impact it has on it. It is evident that the death phenomenon itself is very complex; even as a book about death and dying is taken from scientific literature on psychology of death, it is difficult to predict its object: it can be a statistical analysis of causes of death, the studies on dying people, the mourning, experienced by relatives after loss, the economic death analysis or analysis and research on healthy adults' encounter with death.

According to observations of scientists (Mikulincer \& Florian, 2008; Wong, 2008; Neimeyer, 2008), the research on encounter with death anxiety and perception of own mortality lacks deeper understanding of phenomenon and often a philosophical foundation. The attempts to remain scientific and to maintain an accurate focus on specific research have impoverished the researched phenomenon itself; holistic approach is often ignored, while narrow-field research is more popular. The present research will follow Heidegger's (1992) view towards death, while the human life is considered as being-towards-death. In this context, the concept of finality of life seems more appropriate than the concept of death anxiety. The term of finality of life does refer to the event that terminates the life, but rather emphasizes what is happening in the life process, refers to the death phenomenon in the context of life. During the process of operationalization of the main concept, while carrying out intelligence research, it was revealed that the question about death anxiety is completely incomprehensible to people. It is obvious that it is more a psychological construction than the actual experienced phenomenon. The wording of concept about finality of life and its experience used to be clear and acceptable enough for the surveyed ones, in order they could disclose and share their unique experience.

Furthermore, while exploring the encounter with death, it is recommended to avoid links with other fields, which might have a significant impact on the experience of anxiety. It is recommended to avoid surveys with people, who experience severe, critical or traumatic situations, since it gives a certain shade to research. In order to maintain a purity of phenomenon under research and in order it would not be affected by any extraneous factors, the age of people is also limited. In research, the attention is paid only on age of early maturity, the so-called young adults. This age is the period of matured adults, usually with maximum strengths, when they have the lowest number of health problems (Levinson, 1978).

In this context, the methodology, used by grounded theory, seems to be logical and acceptable, since it enables to review the phenomenon under research in a broad and comprehensive manner by presenting a substantive theory, which explains it, while the usage of selected concept is in line with research method and allows exploring the phenomenon without distorting its essence, without prenarrowing it. What is more, the aforementioned method enables to go deep into the group of certain age (e.g., young adults) and to indentify the categories and their interrelationships. Thus, the aim of the present research was to reveal the experience of finality of life of young adults and to develop a substantive theory, based on the experience of young participants. It is expected that a broader research on the elements and process of experience of finality of life will allow deepening the understanding of this phenomenon and improving its bases, since the currently existing knowledge in scientific literature is insufficient.

\section{Methodology of Research}

The classical grounded theory (GT) method (Glaser, 1978, 1998, 2001) was chosen for the research, which was the most appropriate for achieving the set aims. During classical GT research a researcher can be flexible and start from his curiosity by knowing that "all is data" (Glaser, 2001), and continue further by following the surveyed ones, coming into place, where there is their main concern and trying to understand, how it is solved. A successful research provides a theoretical construct, a substantive theory, which explains the researched phenomenon, enables to understand it better and to research it further. 
18 healthy adults of both genders, aged $22-45$, participated in the research. This number of participants was sufficient, in order to saturate the main categories. 2 in-depth interviews were conducted with each of the participants. The period between the interviews was least one month. They wrote a diary on the topic during that period. The duration of first interview was about 1 hour, while the second lasted for shorter time. The people, who met the research requirements and the criterion of theoretical sampling, and who are able to reflect on their thoughts and to verbalize them, were selected for research. They voluntarily agreed to take part in psychological research and confirmed the consent to participate and to use their anonymous data for scientific purposes. They were also informed about availability of assistance in case of facing difficulties, related with the research topic.

While carrying out the research, according to GT principles, a researcher follows the principle of "full package" (Glaser, 1998) and implements the following processes: 1) problem identification; 2) theoretical sampling; 3) data collection; 4) analysis; 5) writing up the memos; 6) theory development. It is evident that it is possible to describe and name the individual GT steps, however, it cannot be called a linear process. This systemic method is cyclical and a researcher is constantly "walking in circles" among data collection, analysis, conceptualization, writing up the memos, and returning to data collection, etc. Thus, the aforementioned principles were also following during this research, data are collected and analyzed simultaneously. As the data from interview started indicating that theoretical saturation is achieved, data collection was stopped. While coding, the method of constant comparison was followed, when the events are distinguished during open coding and then they are compared with each other, later - with emerging concepts and again with each other, and with emerging wider and more abstract categories. When the core category emerged, it was moved to selective coding by maintaining the focus on the core category. According to Glaser (1978), the core category expresses the main concern of all or almost all participants in an abstract manner. During theoretical coding and while sorting the conceptual memos, the relationships between the core category and concepts are looked for. The sorted memos make the theory in the final stage, which in this case is striving to live more valuably. Moreover, it should be noted that GT must be conceptual, which means that the developed concepts must be independent of time, place, people (Glaser, 2001).

The research was carried out by following the requirements of classical GT methodology: first, the research and analysis was carried out and only then, when the first contours were obtained, the analysis of scientific literature takes place. Thus, it is ensured that the obtained results of research are based on empirical data, appeared from the real experience of research participants and not from hypotheses of scientific literature.

\section{Results of Research}

First of all, GT pays attention on how the participants solve their main concern (Glaser, 1998), therefore, it is preferred to start from its naming. No matter of how the main question is formed or how the experience of finality of life of participants is accessed, the most important thing here is how to accept the fact that "I will die one day" and "cannot do anything" for that, death becomes noticeably inevitable. A person feels, perceives and shortly experiences the inevitability of death. As the interview starts, the first thoughts and comments are always about death and how this phenomenon, which is near and causes confusion, anxiety and other strong feelings, is noticeable in life. At the same time this experience is accompanied by clear understanding that "my personal" death is inevitable - it is like "tangible", and it will certainly come one day, and I will not escape from it and not get out of it.

All participants immediately recall a lot of situations of different and various natures, how they faced the proximity of death, felt a tangible inevitability of this fact and understood its presence. Usually, both the situations of personal encounter with death and becoming a witness of other people's encounter with death are named. These can be very significant, stressful situations - not only bereavements, but also everyday events, for example, the accidents, which failed to cause a lot of damage. It might include the self-imposed situations, fantasies or just memories, when the death was near, or mentioning the death in news programs and poetry.

Regardless of age or experience, all participants have memories, experiences, thoughts, ideas, philosophical insights about death and its meaning, impact on human life. The experience of finality of life always starts from naming the fact of death and understanding that it is near, while its inevi- 
table invasion into life is constantly emphasized. It is often highlighted that these questions arouse in childhood or adolescence. It is emphasized that there is a lot of information, reflections and a wish to share them. Usually, naming the death causes a lot of strong feelings as anxiety, fear or confusion, however, a person tries to control himself and remain calm, even to demonstrate courage.

\section{Striving to Live More Valuably: Reviews and Features of the Theory}

"Thus the goal for a research using grounded theory is to discover the core variable as it resolves the main concern" (Glaser, 1998, p.115). What a man, who faces the fact that the death exists and it is inevitable and is somewhere very near, should do? The category "striving to live more valuably" in this research is one of the ways the healthy adults solve their perception of proximity of death and is a central topic, the naming of which provided the possibility to link the data that were collected during this research. The core category - "striving to live more valuably" - clearly specifies and distinguishes a few things. First of all, it is an obvious opposition to the concept of death. All participants talked about life and clearly understood that as long as there is no death, there is life, thus, our conversation used to naturally turn to their life. What is more, it is always the conversation about life, which is important and valuable for them, about how they understand what is subjectively valuable for them. The following different value aspects can be distinguished: condition facilitation, satisfaction with life.

During research and conceptualization Glaser's (1998) suggestion that "the smaller the amount of concepts that account for the greatest variation in substantive behaviour resolving the main concern is the goal" (p. 190). Thus, 2 substantive categories, which were related with the main concern of participants, emerge along the core category through a constant comparison: "negotiating reality of death" and "negotiating changes in life"; and 4 contextual concepts comprehensive link, constant negotiation, individuality and affectability. As all these categories were combined, the main theoretical construct was formed, which explains the dynamics that takes place as a young adults face the finality of life.

The categories, mentioned in the theory "striving to live more valuably", are interrelated and intertwined. The present research attempts to "extract" and isolate each category separately - by describing and explaining it. It is known that in order to try to understand and explain the researched phenomenon, the amount and interrelationship of these categories must be borne in mind. Figure 1, showing the main elements and concepts of this theory, is presented below.

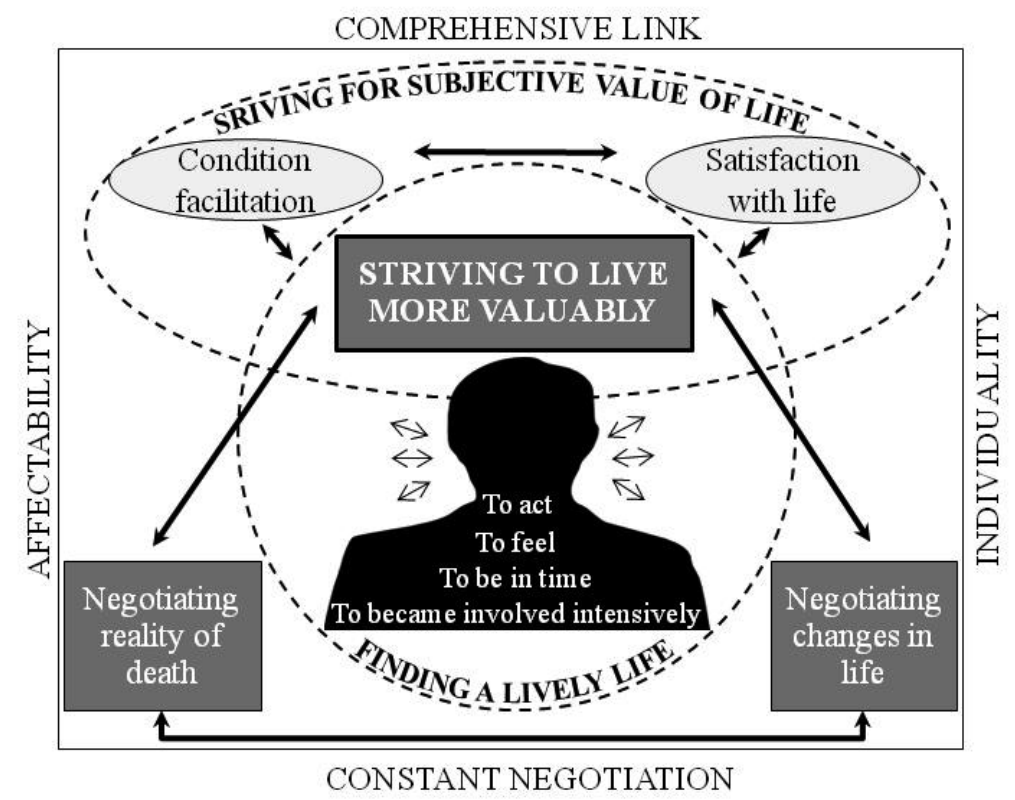

Figure 1: Theoretical structure of "striving to live more valuably" revealing the experience of finality of life. 
The entanglement and overlap of these categories is the essence of aforementioned theory. It is also well reflected by the concept of comprehensive link. During the present research, the interviewees often switched from one to another topic - from death to life. While talking, they used to emphasize "entanglement" and natural indivisibility. The words "related", "network", "intertwined" were directly used during conversation by demonstrating and illustrating the inability to dissociate, by highlighting the relationship among many things, by paying attention on the link between death and life, the relation of world with experiences and well-being, human relationship, the relationship with the next world, etc.

The other concept reflects in the theory as emphasis of "negotiation" and "striving" in the core categories by showing that they are not static processes, but a constant movement, which takes place both among the categories and in the categories. Some people consciously understood and reflected this dynamic aspect - constant negotiation - by naming it clearly. While other people used to express it in words without full understanding of that impact. It is obvious from the data obtained that a person is no longer the same after certain events, insights and changes. His relationship with himself, the world and other people changes inevitably. It forces to reconsider a number of beliefs, values and other basic issues. For example, after hearing about illness of close friend, various processes, which affect many different fields, start taking place inside. The other very typical example is that while celebrating the anniversary, the life changes, the values or value of relationships are reflected on. It is evident that the element of "constant negotiation" is inevitable search by person for answer one has to find to feel better and to change the condition, which appeared as the life situation changed (in this case, as it was heard about illness of friend).

This substantive theoretical model refers to healthy young adults. However, it is obvious that these participants have a quite different personal experience, knowledge and skills to overcome the difficulties of life. It is very difficult to talk about the mentioned group of broad range of age as about homogenous one. Even without going deep into different age and related life experiences, it is evident that the participants of this research were quite different people with different understanding of value of life, different self-reflection level and ability to share their experience with other person (researcher). It is obvious that both different personal structures and different experiences and knowledge are related not only with the fact that a person takes part and talks during research, but also with how he functions in life, how he overcomes the difficulties, how he accepts the challenges of life. It is evident that the extent of "success" of "striving to live more valuably", the extent of efforts, distractions and difficulties a person will encounter in this path is closely related with a person himself. This phenomenon is described by the concept of individuality, thus, keeping the abstraction of "time, place, people".

While facing the stories of participants during interviews and through diaries, it can be seen that this topic involves, prevents from being indifferent, forces to express the position both in respect of own experiences and by being interested in position of other people or just simply speaking on this topic. One cannot remain neutral in the topic of finality of life. It also reveals itself through intense experience by remembering the events or experience and sharing them, and by feeling the need to present own position or assess other people. Even the arising desire to defend or simple avoidance shows that it is impossible to avoid involvement, to remain unaffected, neutral. The aforementioned phenomenon is generalized by the concept of affectability in the theory and it exists during the whole period of research by playing an important role in individual categories. It seems that a person can provide a number of reactions, which are very different and individual, more or less adaptive, with different emotional colours, more or less defensive, however, one or another reaction is always quite intensive. Both while speaking on this topic during interview and later filling the diary or meeting during second interview, a person is full of various ideas, considerations, overestimations and underestimations, and demonstrates a great interest in the results of work and thoughts of other people. Irrespective of kind of reactions provided, of number of experiences and of number of sharing the experiences, they are certainly not neutral and always hide the originality and individuality of position of person. Even if this evidences by strong avoidance and passionate attempt to devalue the experience, it is also a reaction.

Thus, the core category of finality of life, i.e., striving to live more valuably, emerges in above described context of concepts. This category consists of two sub-core categories: finding a lively 
life and striving for subjective value of life. The core concept of the category contains and assimilates the mentioned sub-core categories, which are the main characteristics and components of this core category. In this way the axis is formed around which the grounded theory revolves. The aforementioned sub-categories and their sub-concepts are described in details in further parts.

\section{Finding a Lively Life: A Sub-core Category}

The encounter with death is always accompanied by experience of sudden and intense vitality, which can be illustrated by slogan "but I am still alive!" The aforementioned experience in the present paper is conceptualized as finding a lively life. Being near death, which contrasts with life, strongly intensifies the experience of this vitality. It is not always important how a person encounters death: whether it is the "everyday" death observation or experience of more stressful event, or just intellectual reflection on death - it is accompanied by a sudden and intensive feeling of vitality, which later is named as "as far as there is no death here, I am alive". What is more, it should be noted that although this experience of vitality is accompanied by euphoric tone, it is not always pleasant due to its high intensity and result fairly strong anxiety. 4 quite clear characteristics, accompanying the experience of vitality, can be distinguished: to act, to feel, to become involved intensively and to be in time, which not only helps to feel vitality, but also fixes the vitality in the experience of finality of life, thus, further pulling back from inevitability of death. It is like the mechanisms, when you get involved by life itself and when it does not allow a person to escape from his vitality.

It is important to mention that as people encounter the finality of life and name their death as a tangible one, they quite quickly move to their life and taking care of it. The transition from death to life is a typical action, even if the participants cannot realize it (although usually they do realize). The data of research include many examples, showing that, in principle, people focus on their life and try to look for other forms, situations or conditions, where they would feel better, while meeting the inevitable fact of finality of life, and attempt to make some kind of actions, which could influence the life and its value. Even they consider about death, more specifically, about the process of dying, people look for the ways, how they could feel better in aforementioned process as they are still alive, thus, the focus turns on life.

\section{Striving for Subjective Value of Life: A Sub-core Category}

After passing from death to life and discovering the life with his possibilities, a person tries to live in a subjectively meaningful way and set out his priorities. A person starts looking for and actively seeking what he would call value. Here, the personally experienced subjectivity becomes very important: a person appreciates only that, what is valuable for him. Even if the moment of value is not a long-term one, it shortly exists in the mind of person and, thus, motivates a person to follow it. It should be noted that the phenomenon of value may become more active or emerge very spontaneously and suddenly, when a person appears in the situation of finality of life (e.g., sees the accident and suddenly realizes that instead of working he will spend the evening with family and the loved ones, because it is more important for him), or it might be the result of long-term search, when a person has been looking for and could not find a valuable life path for years. The effect and the extent of intensity of persistence of this behaviour or trait, the extent of its value not always depends on duration of search, it more depends on the value a person assigns to the phenomenon and experience. Usually, he implements it in two ways: by looking for satisfaction with life and condition facilitation. It should be noted that these are not contradicting phenomena. They can take place simultaneously in a man and influence each other. These two concepts of striving for subjective value of life will be discussed in details by highlighting their essential features.

\section{Satisfaction with Life}

The concept of satisfaction with life is described by some features, for example, subjective value, self-being and sufficiency, which are discussed below. The issue of subjective value becomes 
very important in the background of finality of life. It seems that while facing the possibility of death and realizing (although for short time) the possibility of disappearance, a man immediately Volume 5, 2013 faces the question of what is valuable, meaningful, and starts seeking this value. While looking from a side, it is sometimes difficult to understand the aforementioned value, since it is not always seen, however, a person usually has explanations and asks himself, what is valuable for him at that moment: it can be getting drunk with friends in a bar, celebrating the false diagnosis of terminal illness, quitting the job, leaving the annoying wife, faith in God, etc. Regardless of whether it meets the public norms or not, it is important that it is valuable and meaningful for him, that it has a subjectively experienced value. What is more, this issue of value can also include very broad fields: it can be simple physical things (e.g., purchase of items, which have been wanted for a long time), social matters (e.g., remembering the people, who have not been visited for a long time), personal (e.g., decision not to listen to others' opinions), spiritual (faith in God), ethical (identification of important values). It seems that a man gets free then and allows himself starting behaving in the way he wants - in the way that seems valuable for him.

It is important that the need of value and the corresponding behaviour are accompanied by the strong feeling that it is really me, which can be described as self-being. It is the feeling, when a person recognizes himself in that behaviour, when that behaviour makes him more himself. By continuing to behave in the way described above, he more experiences the satisfaction with what he does, creates, selects. It becomes as a clear opposition to alienation - a clear understanding of what really does not exist, what is completely alien. It is focused, following the aforementioned feeling of self-being. It becomes as internal compass, a person starts feeling, what is own and what is not. It is important to note that the experience of self-being leads to great satisfaction and encourages continuing the activity without being interested in how it is assessed by others.

The concept of sufficiency is the experience, born in the context of finality of life, when a person realizes that he cannot have everything, reach everything, do everything, experience everything, and starts looking for the extent, which would be sufficient for him, or realizes that what he already has or has already experienced is sufficient. It is like a change in coordinate system: it is moved from absolute measurement to very specific measurement. The experience of sufficiency is often accompanied by a sense of relief and usually gives inner satisfaction.

\section{Condition Facilitation}

One more not less important striving for subjective value of life is person's concern about condition and striving to facilitate it, thus, ensuring his well-being. It is reflected by concept of condition facilitation. As a person encounters the finality of life, he starts actively looking for what to do, what to perform, in order it would be easier for him, in order to reduce the internal stress, which appears as inevitability of death is realized. Condition facilitation has two characteristics: search for facilitation and fading away. As a person encounters the finality of life, he becomes constantly concerned with his condition. It is worth mentioning that the concern about it is very valuable. Sometimes, the concern about condition may coincide with striving for subjective value of life, while certain condition achieved is like the greatest symbol of value.

It is obvious that as a person encounters the finality of life, he immediately starts looking for something that would help him to feel better, since he experiences anxiety at that moment (even if it is not always named) and under its influence gets actively involved in it, the search for facilitation starts. A part of energy is devoted to "taking care" of that he would feel better, one or other active efforts are made, in order to achieve the aforementioned facilitation. A man notices that he tries to practice the favourite activity, to be with the loved ones, to become involved in usual routine activity, thus, often trying to forget about the death and finality of life. Sometimes, a person denies or tries to distance himself from the thoughts, fantasies or memories, related with this experience, and he even does not allow touching them anymore. Denial is probably one of the most frequently encountered phenomena: when a person openly recognizes (although previously saying otherwise) for both himself and researcher that he does not feel anything, does not experience anything, does not think about death or finality of life at all. It is often possible to feel that failure to think and ability to deny is a great value and is considered as a result of successful 
inner life and work. While the moments, when fear is experienced, are considered as foolishness, weakness or inability to cope with internal disorder. The search for facilitation is also often observed, when avoiding thinking or doing something that is related with experience of finality of life. Thus, it is attempted to protect oneself in advance from difficult experiences and facilitate the condition before the concept of affectability takes place. The mechanism of avoidance is well reflected in a diary, when it was observed, how it is difficult to force oneself to think and write on this topic, even if there were enough thoughts and wish.

The concept of fading away is like the opposite mechanism, which helps to facilitate the condition, however, it often takes place without intervention of human will and only its result is usually observed, which frequently surprises a person himself. While search for facilitation is more "acute" phenomenon, fading away is a "chronic" one. It is a gradual, not sudden, internal work, which lasts for a certain time and which is like a resistance to the mechanism of affectability. While affectability involves actively, fading away "pulls out" a person often without noticing. It is like the other side of concept of affectability, when a person becomes less affectable. This concept is often described by people as the reaction of "forgetting". It is probably best illustrated by understanding, which became apparent during the second interview, that participants think about experience of finality of life far less than they thought during the first interview. This experience is often accompanied by surprise, since during the first interview people usually tell that they often think about death, finality of life, have many thoughts and related experiences. It is often stated that the thoughts about death are very common phenomenon. A person, met after some time, reports with surprise that he had thought far less. As in case of writing a diary: during the first days a man faced an abundance of ideas, which used to die away, and sometimes the desire to write something more even disappeared.

The present article focuses only on the core category, however, as it has already been mentioned and illustrated in Figure 1, two other topics obviously dominated in research. Later, these topics were given the titles of two significant categories: negotiating reality of death and negotiating changes in life. The mentioned topics will not be presented in details. It is just sought to show that striving to live more valuably is strongly related with that what relation or control version, theoretical view is chosen by person in respect of his death and how he accepts his life changes, for example, aging, crumbling relationship, etc.

\section{Discussion}

The term value is rarely mentioned in the literature on death research and death anxiety. It is even less stated that the value is the core element, speaking about encounter with inevitability of death, personal mortality and the resulting feelings and experiences. However, precisely the value plays a central role in this theory and enables to understand the experienced process better. The term "more valuably" is perfect for reflecting the fact that these changes (sometimes, not changes, but just adaptation or calming) take place not chaotically and randomly, but in very targeted manner by emphasizing what is valuable for person at that moment. It is important to note that the opposite things can also be very valuable. Therefore, the subjective value in this theory is also experienced as from two sides: through attempts to find satisfaction with life and through condition facilitation. There is abundance of ideas, grounding the significance of aforementioned concepts, in the literature on death anxiety. However, its one or another aspect is more often highlighted, therefore, we will review them.

Various mechanisms of denial, avoidance, distortion are used and emphasized in psychology. They are most prevalent, when speaking about death anxiety or other encounter with death. "Because we cannot live frozen in fear, we generate methods to soften death's terror" (Yalom, 2008, p. 17). For some purpose, the first striking thing that was noticed, as it was started being interested in this topic or while conducting interview with participants, is the great extent to which people "defend", while talking about death. Therefore, one of the elements of subjective value of life in this research is condition facilitation. It is evident that a man is engaged in a lot of activities, in order to facilitate his condition, to start feeling better, since as a man encounters death and his mortality, he immediately starts taking care of his condition. However, the present research 
attempts to draw attention on the fact that aforementioned behaviour - taking care of condition, sometimes preventing oneself from seeing, thinking about death or attempts to forget it - has a value, since it is easier for a person. The present theory emphasizes that taking care of condition is very valuable phenomenon for a person and not only denial and inaccurate reflection or distortion of reality. Mikulincer and Florian (2008) often emphasize that adding additional factors rather than just focusing on defence mechanisms can determine the success of deeper understanding of death phenomenon. Thus, while talking about death one has to speak about life too. It is important to note Tillich's (1999) idea about courage to be and human ability to turn around and have a brave look at situation and life in the face of obligation to die. In some sense, the research reveals that despite of threat of death, a man turns to life. It is one of key elements of this theory, it is the feature of the concept finding a lively life to shift from death towards life.

According to Moore and Williamson (2003), and Mikulincer and Florian (2008), there is no doubt that the phenomenon of death understanding is very difficult, multidimensional and complex construct, and people differ not only by intensity of experienced fear or anxiety, but also by meaning, which they assign to death and concern, experienced and expressed when facing the death in reality. For example, meaning management theory (Wong, 2008) draws attention on the fact that in order to understand the relationship of person with death and mortality, it is not enough to talk about avoidance of death, it is necessary to speak about human wish to have a nice, happy and meaningful life. In this research, it is illustrated by the concept of subjective value, which specifies that a man seeks to experience value and meaning, in order everything he does would not be empty, meaningless or useless. However, a constant emphasis on the term "subjective" value should be noted. A value, as a meaning, which is discovered and important for man, is not abstract, but very individual. According to Frankl (1998), it is impossible to define the meaning of human life as it is impossible to answer the questions about meaning by general statements. Similarly, a personal subjectivity, emphasizing the fact that what is subjectively valuable in the experience of finality of life for one person can be incomprehensible and obviously meaningless for other person, is of utmost importance in the present research. It seems like contradicting with statement of representatives of terror management theories, i.e., Solomon, Greenberg and Pyszczynsky (1991), that identification with standards of certain culture or identification with specific system helps people to experience the finality of life in an easier manner. It is strongly related with the concept of self-being that the need of value and the resulting behaviour is accompanied by strong feeling that it is really me. It is the feeling that a man recognizes himself in this behaviour, that he becomes more himself by this behaviour. Here, it is important to mention Heidegger (1992) and his ideas about authentic life, since he emphasizes that the nature of death and possibility enables to disclose the structures of authentic being. Similarly, the participants of research sometimes succeed to discover their self-being, which could be understood as authenticity, through encounter with inevitability of death. The concept of sufficiency is also characterized by similar relation, when a man no longer seeks the vague ideals of perfection, but looks for clear and specific things, is able to experience the feeling of sufficiency, while facing both everyday matters and more important events of life. It is related with rapprochement of Rogers' (2005) "real self" and "ideal self". As a result, there is less stress and the relief comes. Here, it might be related with Neimeyer and Chapman's (1980-81) research, when they followed the idea of Sartre (1956) that death will be more frightening for those individuals, whose life project is incomplete, because death will have the action of terminating the life and will be incompatible with sufficiency of realization of ideas. Similarly, the present research demonstrates that sufficiency has a meaningful value and is a part of satisfaction with life.

The theory striving to live more valuably constantly refers to striving and constant movement, which is called a constant negotiation in the present paper and illustrates a dynamic aspect. The word to negotiate at first seemed too managerial and not exactly revealing the psychological picture of a man, however, the attempts to find the concept, which would outline the researched phenomena more accurately, have been unsuccessful. This term is also used in Kubler-Ross' (2001) papers, where she calls the third stage of encounter with death as negotiation. Perhaps the author more emphasizes the human desire to postpone the verdict of fate by changing the behaviour, lifestyle, habits through negotiation with God (or some other higher power). However, the present research also felt the attempts of person to negotiate, confer, look for some ways out and solutions 
by making various dialogues with themselves, facts, other people, with events or changes in the life. Therefore, the term "to negotiate" seemed to be appropriate for expressing a constant movement and attempts to find a personally suitable position.

The present research shows that it can be seen that one cannot remain neutral in the topic of finality of life. The theme of encounter with inevitability of death involves, prevents from being indifferent, forces to express the position both in respect of own experiences and by being interested in position of other people or just simply speaking on this topic. This phenomenon has been relatively little described and explored in the literature. Perhaps the closest would be the mortality salience, proposed by authors of terror management theories (Schmeichel et al., 2009). It is obvious that the future research should explore the phenomenon of affectability more, in order to describe its impact and levels more accurately. Terror management theory mainly deals with influence of self-esteem (internal and external) and its protective function from mortality salience (Solomon et al, 1991; Herman-Jones et al., 1997; Schmeichel et al., 2009). However, as it has already been mentioned, affectability is a broader concept, which includes not only the embarrassing death events, but also aging, as well as events that seem not to be directly related with mortality, for example, celebrations and anniversaries, and sometimes even wedding. It is evident that this topic has not been exhausted yet and requires further analysis and deeper understandings.

As all researches are characterized by unique limitations, this research also has some. Some limitations were related with the topic itself, its conceptual confusion, resistance of people to be open and at the same time the great desire to talk about death and finality. Furthermore, other limitations were related with methodological nuances, with classic GT itself and its aim to develop a specific theory: when the maximum conceptualization was sought and when it was distanced from specific person, place and time. It is obvious that the selected method limited and at the same time enabled to explore the topic of finality of life in precisely this way. It dictated both the originality of research, the number of participants, type and presentation of results, adaptation possibilities. While carrying out the research and preparing this paper, the requirements of "full package" were followed without omitting any significant working procedures, using the necessary research instruments and following the ethical and transparency requirements. However, it was often pity to "sacrifice" the interesting experience of people, significant quotes by hiding them in abstract codes, concepts and categories. Despite this fact, with the help of conceptual categories it was possible to develop and expand the theory itself. What is more, the question how the theory would look like, if we selected other core category, remains open. GT seeks not to create a precise and universal truth, but to develop a theory with meaning both in substantive field, where the research is carried out, and for those, who concern about this phenomenon. There is no one way to examine the data as there is no way to explain the theoretical model, especially, when talking about such complex phenomenon as finality of life. In this case, one has to block his fantasy and leave it for further research. Therefore, the evaluation of theory "striving to live more valuably" should be left for further research by using other methods of empirical research. There is an increasing number of data about usage of structural equation modeling to test the core elements of GT theory and their links in the literature (Rosenbaum, 2012). What is more, it also should be noted that this research was carried out in Lithuanian language, while translation to English was obviously an additional step, which inevitably affected and influenced the concepts and their wordings. Recently, the articles, stating that translation is additional GT work and action, have appeared (Tarozzi, 2012). However, we do expect that despite the aforementioned limitations, the theory will help psychologists, psychotherapists or other professionals, who face this phenomenon in practice, to understand its structure and change better, and will help to draw attention on importance of value, experienced in the background of finality of life, and will stimulate to go deep into what is valuable and important in the life of a person.

\section{Conclusions}

As encounter the finality of life, healthy young adults are "thrown" into experience of inevitability of death and already during interview try to reflect, what is happening with them, attempt to cope with this experience, seeking to live more valuably and increasing the value of their life. 
The theory striving to live more valuably attempts to explain and conceptualize how they experience and deal with, when facing the finality of life. The centre of aforementioned theoretical structure is a person, who is placed to the field of comprehensive links thanks to his individuality and affectability, thus, forcing him to look for solution by increasing the value of life and to balance between tensions, which appear, while negotiating the reality of death and life changes. By doing so, a person seeks the well-being and value of his life in a few fields: condition facilitation and satisfaction with life. Satisfaction with life is sought through subjective value, self-being and sufficiency. Condition facilitation is thought through search for facilitation and fading away. The theoretical model striving to live more valuably can serve as multifactorial and innovative concept, which can expand and direct future research towards fresher direction, enrich the understanding of death phenomenon and finality of life, and stimulate further empirical research.

\section{References}

Frankl, V. E. (1998). Žmogus ieško prasmès. Vilnius: Katalikų pasaulis.

Glaser, B. G. (1978). Theoretical sensitivity. Advances in the methodology of grounded theory. Mill Valley: Sociology Press.

Glaser, B. G. (1998). Doing grounded theory. Issues and discussions. Mill Valley: Sociology Press.

Glaser, B. G. (2001). The Grounded theory perspectives: Conceptualization contrasted with description. Mill Valley: Sociology Press.

Harman-Jones, E., Simon, L., Greenberg, J, Solomon, S., Pyszczynsky, T., \& McGregor, H. (1997). Terror management theory and self-esteem: evidence that increased self-esteem reduces mortality salience effects. Journal of Personality and Social Psychology, 72, 24-36.

Hayes, J., Schimel, J., Arndt, J., \& Fautcher. E. H. (2010). A theoretical and empirical review of the death-thought accesability concept in terror management research. Psychological Bulletin, 136 (5), 699-739.

Heidegeris, M. (1992). Rinktiniai raštai. Vilnius: Mintis.

Jurgaitytè-Avižinienè, A., Kočiūnas, R. (2004). Gyvenimo baigtinumo klausimas psichologijoje. Antroji pasaulio Lietuviu psicholgoju konferencija. Konferencijos medžiaga. Vilnius: Vilniaus Universitetas. 47-48.

Kubler-Ross, E. (2001). Apie mirtị ir mirimq. Vilnius: Katalikų pasaulis.

Levinson, D. J. (1978). The seasons of a man's life. New York: Ballantine Books.

Mikulincer, M., \& Florian, V. (2008). The complex and multifaceted nature of the fear of personal death: the multidimensional model of Victor Florian. In A. Tomer, G. T. Eliason, \& P. T. P. Wong. (Eds.), Existential and spiritual issues in death attitudes (pp. 39-64) New York, NY: Lawrence Erlbaum Associates.

Moore, C. C., Williamson, J. B. (2003). The Universal fear of death and cultural response. In C. D. Bryant (Ed.), Hanbook of death \& dying (pp. 3-13). Thousand Oaks: Sage publications.

Neimeyer, R. A. (2008). Introduction. In A. Tomer, G. T. Eliason, \& P. T. P. Wong. (Eds), Existential and spiritual issues in death attitudes (pp. 1-3). New York: Lawrence Erlbaum Associates.

Neimeyer, R. A., Chapman, K. M. (1980-81). Self-Ideal discrepancy and fear of death: the test of existential hypothesis. Omega, 11 (3), 233-240.

Rogers, C. R. (2005). Apie tapimq asmeniu: psichoterapeuto požiūris ì psichoterapijq. Vilnius: Via recta.

Rosenbaum, M. S. (2012). From theoretical generation to verification using structural equation modeling. In V. B. Martin, \& A. Gynnild (Eds.), Grounded theory: The philosophy, method, and work of Barney Glaser (pp. 283-295). Boca Raton: Brown Walker Press.

Sartre, J. P. (1956). Being and nothing. The essay on phenomenological ontology. New York, NY: Philosophical library.

Schmeichel, B. J., Gailliot, M. T., Filardo, E., McGregor, I., Gitter S., \& Baumeister R. F. (2009). Terror Management theory and self-esteem revisited: the roles of implicit and explicit self-esteem in mortality salience effects. Journal of Personality and Social Psychology, 96 (5), 1077-1087.

Solomon, S., Greenberg, J., \& Pyszczynsky, T. (1991). A terror management theory of social behavior: The psychological functions of self-esteem and cultural world views. In M. P. Zanna (Ed.), Advances in Experimental Social Psychology. (Vol. 24, pp. 93-159). San Diego, CA: Academic Press. 
Tarozzi, M. (2012). On translating grounded theory when translating is doing. In V. B. Martin, \& A. Gynnild (Eds.), Grounded theory: The philosophy, method, and work of Barney Glaser (pp. 161-174). Boca Raton: Brown Walker Press.

Tomer, A., Eliason, G. T., \& Wong, P. T. P. (2008). Conclusion. In A. Tomer, G. T. Eliason \& P. T. P. Wong. (Eds.), Existential and spiritual issues in death attitudes (pp. 439-444). New York: Lawrence Erlbaum Associates.

Wong, P. T. P. (2008). Meaning management theory. In A. Tomer, G. T. Eliason, \& P. T. P. Wong. (Eds.), Existential and spiritual issues in death attitudes (pp. 65-87). New York: Lawrence Erlbaum Associates.

Yalom, I. D. (2008). Žiūrèti i saulę. Kaip ìveikti mirties baimę. Kaunas: Žmogaus psichologijos studijos.

Advised by Agne Matulaite, Vilnius University, Lithuania

Received: February 11, 2013

Accepted: March 14, 2013 